\title{
Fractionation sensitivity and dose response of late adverse effects in the breast after radiotherapy for early breast cancer: long-term results of a randomised trial
}

\author{
John Yarnold ${ }^{a, *}$, Anita Ashton ${ }^{b}$, Judith Bliss ${ }^{c}$, Janis Homewood ${ }^{c}$, Caroline Harper ${ }^{c}$, \\ Jane Hanson $^{\mathrm{a}}$, Jo Haviland ${ }^{\mathrm{c}}$, Søren Bentzen ${ }^{\mathrm{d}}$, Roger Owen ${ }^{\mathrm{b}}$ \\ ${ }^{a}$ Academic Radiotherapy Department, The Royal Marsden Hospital, Surrey, UK, b Department of Oncology, Gloucestershire Oncology Centre, \\ Cheltenham, UK, ' Clinical Trials and Statistics Unit, Institute of Cancer Research, Surrey, UK, \\ ${ }^{\mathrm{d}}$ Human Cancer Biology and Informatics, Gray Cancer Institute, Northwood, UK
}

\begin{abstract}
Background and purpose: Unlike squamous carcinomas, breast adenocarcinoma may be as sensitive to fraction size as late dose-limiting normal tissues. If so, fewer larger fractions would be as safe and effective as regimens based on $2.0 \mathrm{~Gy}$ fractions. The first step is to test the effects of radiotherapy fractions $>2.0 \mathrm{~Gy}$ on late normal tissue responses in the breast after tumour excision and radiotherapy for early breast cancer.

Patients and methods: One thousand four-hundred and ten women with T1-3 N0-1 MO invasive breast cancer were randomised between 1986-98 into one of three radiotherapy regimens after local tumour excision of early stage breast cancer; $50 \mathrm{~Gy}$ in 25 fractions (F) vs two dose levels of a test schedule giving 39 or $42.9 \mathrm{~Gy}$ in $13 \mathrm{~F}$ over 5 weeks. Fraction sizes were 2.0, 3.0 and 3.3 Gy, respectively. The primary endpoint was late change in breast appearance compared to post-surgical appearance scored from annual photographs blinded to treatment allocation. Secondary endpoints included palpable breast induration (fibrosis) and ipsilateral tumour recurrence.
\end{abstract}

Results: After a minimum 5-year follow up, the risk of scoring any change in breast appearance after $50 \mathrm{~Gy} / 25 \mathrm{~F}$, $39 \mathrm{~Gy} / 13 \mathrm{~F}$ and $42.9 \mathrm{~Gy} / 13 \mathrm{~F}$ was $39.6,30.3$ and $45.7 \%$, from which an $\alpha / \beta$ value of $3.6 \mathrm{~Gy}(95 \% \mathrm{Cl} 1.8-5.4)$ is estimated. The $\alpha / \beta$ value for palpable breast induration was $3.1 \mathrm{~Gy}(95 \% \mathrm{Cl} 1.8-4.4)$.

Conclusions: An $\alpha / \beta$ value of around $3 \mathrm{~Gy}$ for late normal tissue changes in the breast is derived from the estimated equivalence of $41.6 \mathrm{~Gy}$ in 13 fractions and $50 \mathrm{~Gy}$ in 25 fractions over 5 weeks, in line with trial predictions.

(c) 2005 Elsevier Ireland Ltd. All rights reserved. Radiotherapy and Oncology 75 (2005) 9-17.

Keywords: Radiotherapy; Breast cancer; Fractionation; Normal tissue response

The use of $2.0 \mathrm{~Gy}$ fractions in primary breast cancer radiotherapy is based on the assumption that larger fraction sizes cause a steeper rise in the rate of late adverse effects than in the rate of tumour control, with inevitable compromise of the therapeutic ratio. The relationship between fraction size and tissue response is well described by the $\alpha / \beta$ value in the linear quadratic model of fractionation sensitivity [10]. According to this empirical model, low $\alpha / \beta$ values signify greater sensitivity to fraction size than higher $\alpha / \beta$ values. In squamous cell carcinomas of the head and neck and cervix uteri, indirect estimates yield high $\alpha / \beta$ values of $\geq 7$ Gy for tumour control, compared to 2-5 Gy for late normal tissue responses [3]. These estimates support the choice of $2.0 \mathrm{~Gy}$ fractions for the treatment of squamous cell carcinoma, for example. However, experimental data suggest that other human tumour types are significantly more sensitive to fraction size than squamous carcinomas $[16,17]$. Specifically, $\alpha / \beta$ values of 4-5 Gy have been derived for the radiation response of recurrent or inoperable breast cancer $[6,8]$. Values of 1.8 $2.0 \mathrm{~Gy}$ have been reported for the local control of soft tissue sarcoma $[7,15]$. There are also suggestions that prostate carcinoma is more sensitive to fraction size than previously thought [5]. These estimates suggest that low fractionation sensitivity may not be a uniform characteristic of human cancers. If breast adenocarcinoma is as sensitive, or almost as sensitive, to fraction size as dose-limiting normal breast tissues, including skin, adipose tissue, glandular tissue, muscle and perhaps bone, this has obvious implications for the optimal choice of radiotherapy regimen. If shorter schedules delivering fewer, larger fractions are as, or more, effective than conventional regimens, they will be more 
convenient for patients, provided the total dose is adjusted better than in the past to the tolerance of non-target tissues $[1,9]$.

Against this background, a randomised clinical trial was started in 1986 to test the fractionation sensitivity of breast tissues to modest increases in fraction size above 2.0 Gy. The trial was controlled for overall treatment time and was designed to generate reliable estimates of $\alpha / \beta$ for late changes in breast appearance and induration. It was not powered to generate reliable estimates of $\alpha / \beta$ for tumour control, nor to address patient-oriented functional outcomes and quality of life. The preliminary results of this 'pilot trial' informed the design of the UK Standardisation of Radiotherapy (START) trial launched in January 1999, and the tumour control data from the pilot trial were incorporated into the START trial dataset. The START trial of 4451 patients includes a similar randomisation with tumour control as the primary endpoint and patient self-assessments of functional outcome and quality of life as important secondary endpoints. The independent START Trial Steering Committee has authorised the full publication of the late radiotherapy normal tissue effects of the pilot trial, the subject of this manuscript $[12,21]$.

\section{Methods \\ Patients}

Between January 1986 and March 1998, 1410 patients were enrolled in a clinical trial of radiotherapy dose schedules at the Royal Marsden Hospital (RMH), Sutton and the Gloucestershire Oncology Centre (GOC), Cheltenham. Patients with operable invasive breast cancer (T1-3 N0-1 M0) requiring radiotherapy were eligible for the trial provided they were under 75 years at presentation, had breast preserving surgery and complete macroscopic resection of invasive carcinoma. All patients had level II/III axillary dissection, except for women at RMH over 50 years of age with impalpable axillary lymph nodes, in whom a policy of no axillary surgery or lymphatic radiotherapy was offered, and some women at GOC who had axillary sampling [11]. Patients with positive axillary pathology were recommended radiotherapy to the supraclavicular fossa at RMH, but at GOC it was reserved for patients with heavy node involvement in levels I and II or any involvement in level III. At neither institution was axillary radiotherapy given after axillary dissection, although it was recommended after axillary sampling if the axillary nodes were pathologically positive and at GOC if no axillary surgery had been undertaken. The use of adjuvant systemic therapy was not specified in the protocol, and evolved over the accrual period according to changes in routine local practice. In general, between 1986 and 1990, adjuvant tamoxifen $20 \mathrm{mg}$ daily was prescribed for a minimum of 2 years to women over the age of 50 years, regardless of oestrogen receptor status. After 1990, women $\leq 50$ years were also recommended adjuvant tamoxifen $20 \mathrm{mg}$ daily for 5 years. Between 1986 and 1990, adjuvant CMF chemotherapy was recommended after surgery and delivered either prior to radiotherapy or concurrently with radiotherapy to all women $\leq 50$ years with pathologically positive axillary lymph nodes. After 1990, an increasing proportion of women aged $50-70$ years with positive axillary lymph nodes were offered adjuvant chemotherapy in addition to endocrine therapy.

\section{Trial design, entry procedure and follow-up}

Patients were randomised to three alternative dose schedules delivered over 5 weeks at a ratio of $1: 1: 1$. The control arm of $50 \mathrm{~Gy}$ in 25 fractions over 5 weeks was compared with 2 dose levels of an experimental schedule delivering 13 fractions over 5 weeks (treating five times per fortnight viz. Monday, Wednesday, Friday, Tuesday, Thursday, etc.). The choices of fraction size for the 2 experimental arms were determined by the lower and upper limits of fraction size considered to be equivalent, in terms of late normal tissue responses, to $50 \mathrm{~Gy}$ in 25 fractions of $2.0 \mathrm{~Gy}$. Fraction sizes of 3.0 and $3.3 \mathrm{~Gy}$ were selected, corresponding to $\alpha / \beta$ values of 1.8 and $6.0 \mathrm{~Gy}$, respectively.

Randomisation was achieved by a telephone call to the Clinical Trials and Statistics Unit at the Institute of Cancer Research, Sutton after obtaining informed consent. Patients were stratified by treatment centre and by whether microscopic foci of invasive or intraduct disease was present at or close $(<3 \mathrm{~mm})$ to the nearest surgical margin. In patients with a complete microscopic resection, when the clinician felt it was appropriate and the patient consented, a sub-randomisation to boost versus no boost was performed. This sub-randomisation closed in May 1994, and thereafter, all patients were offered an elective boost. Patients were reviewed 3-monthly to 3 years, 6-monthly to 5 years and annually thereafter. Prospective physician assessments were recorded annually on a trial proforma, including normal tissue effects for 10 years in the first 806 patients. Photographs were taken annually for the first 5 years and then at 10 years in all evaluable patients. Patients agreed to the annual photographic assessments as part of the research.

\section{Radiotherapy}

Patients were simulated and treated in the same supine position, at RMH with both arms abducted and at GOC with one arm abducted. Patients at RMH were planned with the aid of a conventional simulator, whereas patients at GOC were planned using a simulator with axial tomographic facility. During this era, clinicians planned patients by marking $50 \%$ field borders on the skin a minimum $1 \mathrm{~cm}$ outside palpable breast. Megavoltage photons (6 MV X-rays) were used, except for a minority of small-sized patients treated with $\mathrm{Co}^{60} \gamma$-rays or $4 \mathrm{MV}$ X-rays and large-sized patients treated with $10 \mathrm{MVX}$ rays. Wedge tissue compensators were used in all patients, with the wedge angles estimated from a single transverse external contour through the central plane. During the trial period, lung corrections were applied at GOC, but not at RMH. The reference point for tangential fields was in the centre of the breast, midway between the skin entry points of the tangential fields and midway between a perpendicular line from the skin surface to the lung/chest wall interface. The range of doses on the central plane was maintained between -5 and $+7 \%$ of the reference isodose, but 3D dose compensation was not applied. No bolus was applied to the excision scar. When delivered, lymphatic radiotherapy comprised an anterior field to the supraclavicular fossa, using 
the same dose schedule as for the breast and prescribed as an applied dose. If the axilla was included, an equally weighted posterior axillary field was treated with every fraction to ensure that $100 \%$ of the prescribed dose was delivered to the axillary midline.

In all patients allocated to receive a boost, this was delivered by electrons to the tumour bed to a dose of $14 \mathrm{~Gy}$ to the $90 \%$ isodose $(15.5 \mathrm{~Gy}$ to $100 \%)$ in 7 daily fractions.

\section{Definition and assessment of endpoints}

The primary endpoint was late change in breast appearance compared to post-surgical appearance scored from annual photographs blinded to treatment allocation. Secondary endpoints included palpable breast induration (fibrosis) and ipsilateral tumour recurrence.

\section{Photographic assessments of the breast}

Frontal photographs of both breasts were taken after primary surgery, before radiotherapy, and repeated annually for 5 years and then at 10 years under standard conditions in the photographic departments of both hospitals. Two photographs were taken, one with the hands resting on the hips, the other with the arms raised above the head. Followup photographs were terminated in the case of local recurrence, further breast surgery, declining health or patient refusal.

In 7 dedicated assessment sessions over the 17-year period, photographs were scored by 3 observers $(2$ male clinicians and 1 female nurse) blind to patient identity, fractionation allocation and year of follow-up. Comparisons were always based on photographs at two time-points, one showing postoperative appearance and the other showing breast appearance at year $n(n=1-5,10)$. Changes in the contralateral breast made it possible to distinguish radiotherapy effects from other time-related changes, e.g. weight gain. Change in breast appearance compared with the postoperative baseline was scored by each observer, acting independently, on a 3-point graded scale (none/minimal, 0 , mild, 1, marked, 2) based on change in breast size, shrinkage and shape. Breast size and surgical deficit were also scored from the baseline photographs using 3-point graded scales. Telangiectasia was ignored for the purpose of scoring photographic changes (it was recorded on trial proformas at annual follow-up).

All discrepancies between observers were re-evaluated with an additional random subset (approximately 10\%) to investigate repeatability. After the repeat assessment, the modal category was chosen if the observers were still in disagreement. In the case of missing assessments, reason for non-availability was classified as death, too ill (metastatic disease or other concurrent illness) or patient declined (including those unavailable due to change of residence), local recurrence (patient no longer assessable), and missing (administrative error).

\section{Clinical assessments of the breast and arm}

At annual follow-up clinic visits, the attending clinician completed a trial proforma recording breast shrinkage, distortion, oedema, induration, telangiectasia, arm swelling and shoulder stiffness, each on 4-point graded scales (none,
0, mild, 1, moderate, 2, marked, 3). Patient weight was not recorded. Assessments of breast cosmesis were also made (excellent, good, fair, poor). Over the period of the trial, the number of clinicians, including specialist trainees, completing the trial proformas is estimated to be several dozen. In the later years of the trial, the proforma was simplified for new patients and the physician assessments were omitted. Therefore, only patients randomised before this change are available for inclusion in the analysis of the clinical assessment data (806 patients).

\section{Statistical methods}

\section{Photographic assessments of the breast}

Time from baseline to first recording of 'any radiation effect' (grade 1 or 2 ) and the time until 'marked radiation effect' (grade 2) were calculated. Missing data at intervening years were ignored. The probability of not developing late radiation damage by each year of follow-up was depicted over the follow-up period on a survival curve, and the fractionation schedules compared using the Logrank test. Kaplan-Meier estimates of the probability of no late radiation damage at 5 and 10 years were obtained, with $95 \%$ confidence intervals $(\mathrm{Cl})$. Other methods of analysing interval-censored data were explored and found to produce very similar results (data not shown). Cox proportional hazards regression models were fitted in order to obtain direct estimates (with $95 \% \mathrm{Cl}$ ) of the $\alpha / \beta$ ratio for any change and marked change in breast appearance.

Inter and intra observer variability was monitored by comparing photographic scores between observers and also by assessing the reproducibility of scores for each observer by re-assessing a random sample of photographs. Degree of agreement was assessed using a weighted kappa statistic, where the weights were inversely related to the size of differences between grades scored (i.e. equal grades receive highest weight and grades differing by two categories receive lowest weight).

The analysis was restricted to those patients who had at least one follow-up and a baseline photograph with which to compare subsequent changes (1202 patients). Absence of a baseline photograph was usually due to administration problems and did not appear to be related to fractionation schedule.

\section{Clinical assessments of the breast and arm}

Analysis of the annual physician assessments was by calculating time from baseline to first recording of an event, using a method very similar to that used for the photographic endpoint. The time to significant change, defined as grade 2 or 3 (moderate or marked), was calculated. Missing data at intervening years were ignored. Survival curves showing the probability of not experiencing a given event by each year of follow-up were obtained. Kaplan-Meier estimates of the probability of no late radiation damage at 5 and 10 years were obtained, with 95\% confidence intervals. Fractionation schedules were compared using the Logrank test. Due to analysis of multiple endpoints and the inflated risks of observing statistically significant effects that reflect the play of chance, emphasis was given to the most marked effects. 
Cox proportional hazards regression models were fitted in order to obtain direct estimates (with $95 \% \mathrm{Cl}$ ) of the $\alpha / \beta$ ratio for the various clinical endpoints of late radiation effect. The analysis of this endpoint was restricted to

Table 1

Demographic and clinical characteristics of 1410 patients randomised

\begin{tabular}{|c|c|}
\hline Patient characteristic & Number (\%) \\
\hline \multicolumn{2}{|l|}{ Age at randomisation } \\
\hline $20-29$ & $9(0.9)$ \\
\hline $30-39$ & $98(7.0)$ \\
\hline $40-49$ & $316(22.4)$ \\
\hline $50-59$ & $503(35.7)$ \\
\hline $60-69$ & $425(30.1)$ \\
\hline $70-79$ & $59(4.2)$ \\
\hline \multicolumn{2}{|l|}{ Breast size (from photographs) } \\
\hline Small & $186(13.2)$ \\
\hline Medium & $952(67.5)$ \\
\hline Large & $203(14.4)$ \\
\hline Not known & $69(4.9)$ \\
\hline \multicolumn{2}{|l|}{ Surgical deficit (from photographs) } \\
\hline Small & $845(59.9)$ \\
\hline Medium & $415(29.4)$ \\
\hline Large & $76(5.4)$ \\
\hline Not known & $74(5.2)$ \\
\hline \multicolumn{2}{|l|}{ cT stage } \\
\hline TO & $59(4.2)$ \\
\hline $\mathrm{T} 1$ & $749(53.1)$ \\
\hline $\mathrm{T} 2$ & $575(40.8)$ \\
\hline T3 & $22(1.6)$ \\
\hline T4 & $2(0.1)$ \\
\hline TX & $3(0.2)$ \\
\hline \multicolumn{2}{|l|}{ cN stage } \\
\hline NO & $1187(84.7)$ \\
\hline N1 & 219 (15.5) \\
\hline N2 & $3(0.2)$ \\
\hline NX & $1(0.1)$ \\
\hline \multicolumn{2}{|l|}{ Number of nodes pathologically involved } \\
\hline 0 & $564(67.3)$ \\
\hline $1-3$ & $202(24.1)$ \\
\hline $4+$ & $72(8.6)$ \\
\hline No axillary surgery ${ }^{a}$ & $572(40.6)$ \\
\hline \multicolumn{2}{|l|}{ Adjuvant treatment } \\
\hline None & $289(20.5)$ \\
\hline Tamoxifen only & $918(65.1)$ \\
\hline Chemotherapy only & $40(2.8)$ \\
\hline Tamoxifen + chemotherapy & $156(11.1)$ \\
\hline Other & $7(0.5)$ \\
\hline \multicolumn{2}{|l|}{ Axillary/SCF ${ }^{\mathrm{b}}$ treatment } \\
\hline None & $337(23.9)$ \\
\hline Axillary/SCF $\mathrm{RT}^{\mathrm{c}}$, no axillary surgery & $231(16.4)$ \\
\hline Surgery, no RT & $782(55.5)$ \\
\hline Surgery and SCF RT & $59(4.2)$ \\
\hline Not known & $1(0.1)$ \\
\hline \multicolumn{2}{|l|}{ Breast boost } \\
\hline Randomised to no boost & $359(25.5)$ \\
\hline Randomised to boost & $364(25.8)$ \\
\hline Non-randomised boost given & $687(48.7)$ \\
\hline
\end{tabular}

\footnotetext{
a $\mathrm{cNO}$ and over 50 years.

b Supraclavicular fossa.

c Radiotherapy.
}

the cohort of patients with detailed clinical assessment data $(n=806)$.

\section{Results \\ Patient characteristics and follow-up}

The demographic and clinical characteristics of the 1410 patients randomised into the trial are shown in Table 1 . The mean age of patients was 54.5 years (SD 9.7; range 25-78 years). Almost all (93.9\%) of patients were stage cT1 or cT2, and $67.3 \%$ of patients who underwent axillary staging were node negative. The majority of patients received adjuvant tamoxifen (64.0\%), 13.9\% received adjuvant chemotherapy and $20.5 \%$ did not receive any form of adjuvant systemic therapy. Surgery was the most frequent axillary treatment (60.1\%). 16.4\% received axillary and supraclavicular fossa radiotherapy as an alternative to axillary surgery, with an additional $4.2 \%$ having lymphatic radiotherapy confined to the supraclavicular fossa (patients with $\geq 4$ positive nodes or level III involvement). The maximum length of total followup was 15 years, with a median of 8.1 years in patients who remain alive.

\section{Reproducibility of photographic assessments of the breast}

Of the 1410 patients in the trial, 1284 had a baseline photographic assessment and of these, 1202 have at least one follow-up photographic assessment of late normal tissue effects (Fig. 1). The number of pairs of photographs available at each time point was 1128 at 1 year, 1004 at 2 years, 525 at 3 years, 472 at 4 years, 765 at 5 years, and 141 at 10 years. Reasons for non-availability were explored, and no evidence was observed that this was associated with either the fractionation schedule or to the probability of experiencing a future normal tissue event or local relapse.

In the 1202 patients with baseline and at least one followup photograph, a total of 4035 pairs of follow-up photographs have been assessed. Of these, 1058 caused a discrepancy between observers, and the majority of these discrepancies were resolved by repeat assessment. Overall, the percentage agreement between pairs of observers was $81.3,83.4$ and $81.9 \%$ for observers 1 and 2,1 and 3 , and 2 and 3 , when 62.4, 66.1 and $64.3 \%$ agreement would have been expected by chance. These generate weighted kappa statistics of $0.56,0.57,0.55$, all of which are highly significant in this large cohort. Three hundred and eighty

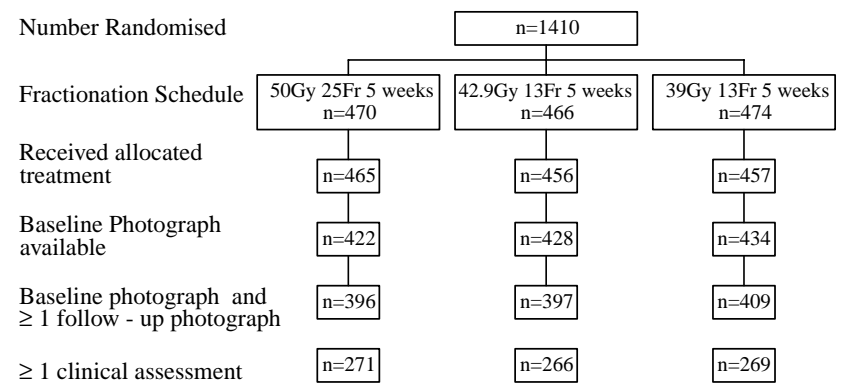

Fig. 1. Number of patients randomised into each fractionation schedule and with available follow-up data. 
Table 2

Survival analyses of change in breast appearance and clinical assessments of late radiation effects according to fractionation schedule

\begin{tabular}{|c|c|c|c|c|c|}
\hline Endpoint & $\begin{array}{l}\text { Fractionation } \\
\text { schedule }\end{array}$ & Events/total (\%) & $\begin{array}{l}\text { Estimated \% with no } \\
\text { event at } 5 \text { years } \\
(95 \% \mathrm{Cl})\end{array}$ & $\begin{array}{l}\text { Estimated } \% \text { with no } \\
\text { event at } 10 \text { years } \\
(95 \% \mathrm{Cl})\end{array}$ & $\begin{array}{l}\text { Logrank test } \\
\text { comparing all } 3 \\
\text { schedules: } P \text {-value }\end{array}$ \\
\hline \multicolumn{6}{|c|}{ Photographic assessment } \\
\hline $\begin{array}{l}\text { Any change in breast } \\
\text { appearance }\end{array}$ & $\begin{array}{l}50 \mathrm{~Gy} \\
42.9 \mathrm{~Gy} \\
39 \mathrm{~Gy}\end{array}$ & $\begin{array}{l}140 / 396(35.4) \\
168 / 397(42.3) \\
112 / 409(27.4)\end{array}$ & $\begin{array}{l}60.4(54.9-65.8) \\
54.3(48.9-59.7) \\
69.7(64.6-74.8)\end{array}$ & $\begin{array}{l}46.6(37.2-55.9) \\
42.0(33.0-51.0) \\
43.9(30.8-57.0)\end{array}$ & $<0.001$ \\
\hline $\begin{array}{l}\text { Marked change in } \\
\text { breast appearance }\end{array}$ & $\begin{array}{l}50 \mathrm{~Gy} \\
42.9 \mathrm{~Gy} \\
39 \mathrm{~Gy}\end{array}$ & $\begin{array}{l}22 / 396(5.6) \\
40 / 397(10.1) \\
14 / 409(3.4)\end{array}$ & $\begin{array}{l}93.6(90.8-96.4) \\
88.8(85.3-92.2) \\
96.1(93.9-98.2)\end{array}$ & $\begin{array}{l}90.2(85.0-95.5) \\
84.4(77.7-91.1) \\
93.4(87.8-99.0)\end{array}$ & $<0.001$ \\
\hline $\begin{array}{l}\text { Clinical assessment } \\
\text { Cosmesis (fair/poor) }\end{array}$ & $\begin{array}{l}50 \mathrm{~Gy} \\
42.9 \mathrm{~Gy} \\
39 \mathrm{~Gy}\end{array}$ & $\begin{array}{l}165 / 271(60.9) \\
175 / 266(65.8) \\
136 / 269(50.6)\end{array}$ & $\begin{array}{l}44.1(37.7-50.4) \\
37.9(31.7-44.1) \\
54.6(48.3-60.9)\end{array}$ & $\begin{array}{l}28.8(22.3-35.4) \\
25.6(19.3-31.8) \\
42.0(34.9-49.1)\end{array}$ & $<0.001$ \\
\hline $\begin{array}{l}\text { Breast shrinkage } \\
\text { (moderate/marked) }\end{array}$ & $\begin{array}{l}50 \mathrm{~Gy} \\
42.9 \mathrm{~Gy} \\
39 \mathrm{~Gy}\end{array}$ & $\begin{array}{l}147 / 271(54.6) \\
148 / 266(55.8) \\
124 / 269(46.1)\end{array}$ & $\begin{array}{l}49.9(43.5-56.3) \\
47.2(40.8-53.7) \\
56.9(50.6-63.2)\end{array}$ & $\begin{array}{l}36.2(29.3-43.1) \\
34.2(27.0-41.5) \\
44.4(37.0-51.7)\end{array}$ & 0.026 \\
\hline $\begin{array}{l}\text { Breast distortion } \\
\text { (moderate/marked) }\end{array}$ & $\begin{array}{l}50 \mathrm{~Gy} \\
42.9 \mathrm{~Gy} \\
39 \mathrm{~Gy}\end{array}$ & $\begin{array}{l}132 / 271(48.9) \\
148 / 266(55.8) \\
115 / 269(42.8)\end{array}$ & $\begin{array}{l}54.6(48.2-61.0) \\
45.7(39.9-52.1) \\
59.3(53.1-65.4)\end{array}$ & $\begin{array}{l}41.5(34.4-48.6) \\
38.0(31.4-44.6) \\
51.4(44.4-58.4)\end{array}$ & 0.005 \\
\hline $\begin{array}{l}\text { Breast oedema } \\
\text { (moderate/marked) }\end{array}$ & $\begin{array}{l}50 \mathrm{~Gy} \\
42.9 \mathrm{~Gy} \\
39 \mathrm{~Gy}\end{array}$ & $\begin{array}{l}34 / 271(12.6) \\
54 / 266(20.3) \\
29 / 269(10.8)\end{array}$ & $\begin{array}{l}87.6(83.6-91.7) \\
80.2(75.3-85.2) \\
89.4(85.6-93.2)\end{array}$ & $\begin{array}{l}86.2(81.8-90.7) \\
78.5(73.1-83.9) \\
88.5(84.4-92.7)\end{array}$ & 0.004 \\
\hline $\begin{array}{l}\text { Induration (moder- } \\
\text { ate/marked) }\end{array}$ & $\begin{array}{l}50 \mathrm{~Gy} \\
42.9 \mathrm{~Gy} \\
39 \mathrm{~Gy}\end{array}$ & $\begin{array}{r}77 / 271(28.6) \\
108 / 266(40.8) \\
55 / 269(20.4)\end{array}$ & $\begin{array}{l}76.9(71.5-82.3) \\
64.4(58.1-70.6) \\
84.0(79.2-88.8)\end{array}$ & $\begin{array}{l}63.7(56.6-70.7) \\
48.9(41.5-56.4) \\
72.3(65.5-79.2)\end{array}$ & $<0.001$ \\
\hline $\begin{array}{l}\text { Telangiectasia } \\
\text { (moderate/marked) }\end{array}$ & $\begin{array}{l}50 \mathrm{~Gy} \\
42.9 \mathrm{~Gy} \\
39 \mathrm{~Gy}\end{array}$ & $\begin{array}{l}37 / 271(13.8) \\
38 / 266(14.3) \\
23 / 269(8.6)\end{array}$ & $\begin{array}{l}88.0(83.8-92.3) \\
87.0(82.7-91.4) \\
94.4(91.4-97.4)\end{array}$ & $\begin{array}{l}81.9(76.5-87.3) \\
82.0(76.5-87.5) \\
88.0(83.0-92.9)\end{array}$ & 0.065 \\
\hline $\begin{array}{l}\text { Arm oedema (mod- } \\
\text { erate/marked) }\end{array}$ & $\begin{array}{l}50 \mathrm{~Gy} \\
42.9 \mathrm{~Gy} \\
39 \mathrm{~Gy}\end{array}$ & $\begin{array}{l}17 / 271(6.3) \\
22 / 266(8.3) \\
16 / 269(5.9)\end{array}$ & $\begin{array}{l}93.8(90.7-97.0) \\
91.7(88.1-95.3) \\
95.4(92.7-98.1)\end{array}$ & $\begin{array}{l}92.3(88.6-96.1) \\
89.5(85.1-93.8) \\
93.0(89.2-96.8)\end{array}$ & 0.494 \\
\hline $\begin{array}{l}\text { Shoulder stiffness } \\
\text { (moderate/marked) }\end{array}$ & $\begin{array}{l}50 \mathrm{~Gy} \\
42.9 \mathrm{~Gy} \\
39 \mathrm{~Gy}\end{array}$ & $\begin{array}{l}21 / 271(7.8) \\
48 / 266(18.1) \\
19 / 269(7.1)\end{array}$ & $\begin{array}{l}94.1(91.2-97.0) \\
84.0(79.3-88.6) \\
94.2(91.2-97.2)\end{array}$ & $\begin{array}{l}90.0(85.6-94.3) \\
78.2(72.3-84.0) \\
89.9(85.3-94.6)\end{array}$ & $<0.001$ \\
\hline
\end{tabular}

seven assessments have been reassessed as a random sample to investigate repeatability. Within-observer agreement was $78.8,83.9$ and $83.9 \%$ for observers 1,2 and 3, respectively, when one would expect $60.4,61.4$ and $68.2 \%$ agreement by chance. In this case, weighted kappa statistics of $0.51,0.61$ and 0.57 are observed, each highly statistically significant. Some variation did appear to exist between assessment sessions but no systematic pattern has been identified.

\section{Sensitivity of photographic assessments to randomised dose}

A total of 420 patients (34.9\%) experienced some change in breast appearance over the follow-up period, which varied between the fractionation schedules (Table 2). Fig. 2 shows the probability of any late radiation effect over ten years following radiotherapy, according to fractionation schedule. There is some evidence of variation in the difference between the fractionation schedules as followup increases, as the 50 and $39 \mathrm{~Gy}$ arms appear to be converging, but analysis shows this not to be statistically significant $(P=0.08)$. The risk of developing any radiation effect is much lower for patients allocated to receive $39 \mathrm{~Gy}$ in 13 fractions compared with those allocated 42.9 Gy in 13 fractions. There is a statistically significant difference between the 50 and $39 \mathrm{~Gy}$ arms of the trial over this time period ( $P=0.01$ for Logrank test), but weaker evidence for a difference between 50 and $42.9 \mathrm{~Gy}$ ( $P=0.05$ Logrank test). The number of patients scoring a grade 2 (marked) change in breast appearance is relatively small, a total of 76/1202

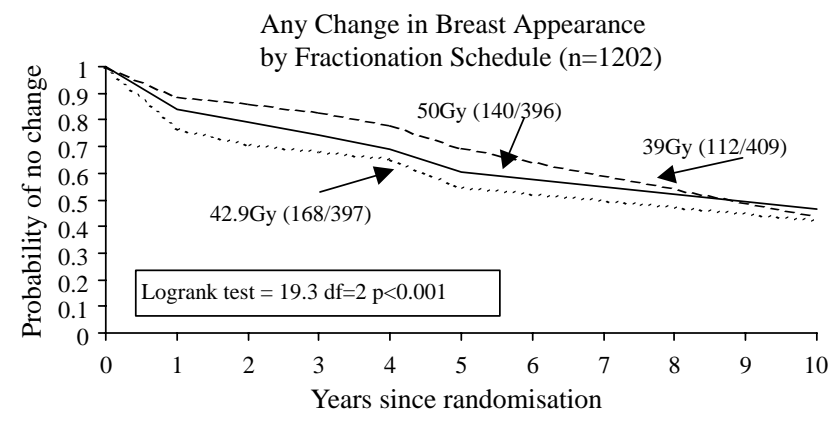

Fig. 2. Probability of any change in breast appearance late radiation effect ten years after radiotherapy by fractionation schedule. 


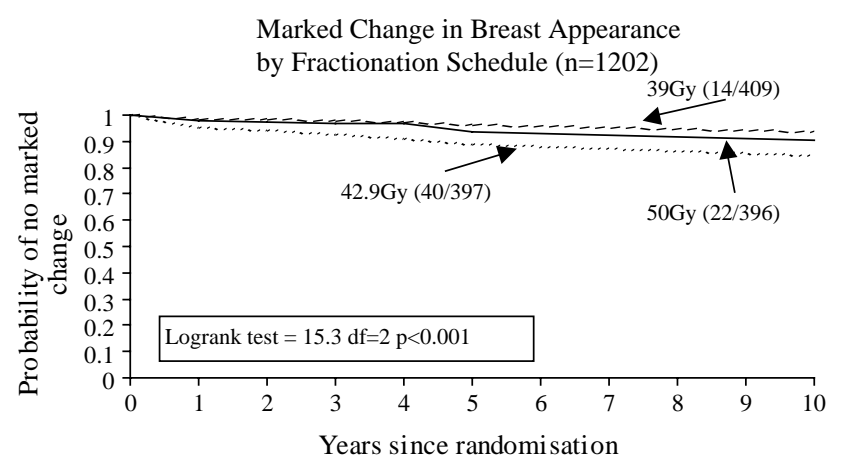

Fig. 3. Probability of marked change in breast appearance late radiation effect ten years after radiotherapy by fractionation schedule.

patients (6.3\%), but evidence is observed of a lower risk of marked change in the patients treated with $39 \mathrm{~Gy}$ compared with 42.9 Gy (see Table 2 and Fig. 3). Similarly, there is evidence of a difference between the 50 and $42.9 \mathrm{~Gy}$ arms of the trial for marked change in appearance $(P=0.01$ Logrank test), but not between 50 and $39 \mathrm{~Gy}(P=0.18$ Logrank test). Kaplan-Meier estimates of probability of no change and no marked change in breast appearance at 5 and 10 years, according to treatment schedule are presented in Table 2. The value of the $\alpha / \beta$ ratio estimated from the Cox proportional hazards regression model for any change in breast appearance is $3.6 \mathrm{~Gy}(95 \% \mathrm{Cl} 1.8-5.4 \mathrm{~Gy})$, and is $2.9 \mathrm{~Gy}$ (95\% Cl 1.0-4.8 Gy) for marked change in breast appearance, see Table 3. The $\alpha / \beta$ values are unaltered if photographic changes scored in the first 12 or 24 months are censored and the analysis restricted to events emerging at $\geq 3$ years (data not shown), in order to allow for earlier, non-permanent, changes in breast appearance due to, e.g. surgical oedema.

An estimate of the steepness of the dose-response curve for any change in breast appearance for a fixed number of 13 fractions was derived from the 10-year estimates in Table 2 using the method by Bentzen et al. [4]. The normalised dose-response gradient at the $50 \%$ response level, $\gamma_{50}$ was estimated at 1.8 with $(95 \% \mathrm{Cl} 0.8-2.7)$. This estimate is obtained for otherwise unselected patients. It is likely that

Table 3

Estimates of alpha-beta ratios for each normal tissue endpoint, obtained from Cox proportional hazards regression analysis

\begin{tabular}{ll}
\hline Endpoint & $\alpha / \beta(95 \% \mathrm{Cl})$, in Gy \\
\hline Photographic assessment & $3.6(1.8-5.4)$ \\
Any change in breast appearance & $2.9(1.0-4.8)$ \\
Marked change in breast appearance & \\
Clinical assessment & $3.8(1.4-6.3)$ \\
Cosmesis (fair/poor) & $4.7(1.0-8.6)$ \\
Breast shrinkage (moderate/marked) & $3.1(1.0-5.8)$ \\
Breast distortion (moderate/marked) & $2.3(1.0-4.5)$ \\
Breast oedema (moderate/marked) & $3.1(1.8-4.4)$ \\
Induration (moderate/marked) & $5.1(1.0-9.5)$ \\
Telangiectasia (moderate/marked) & $2.2(1.0-7.9)$ \\
Arm oedema (moderate/marked) & $1.8(1.0-3.6)$ \\
Shoulder stiffness (moderate/marked) & \\
\hline
\end{tabular}

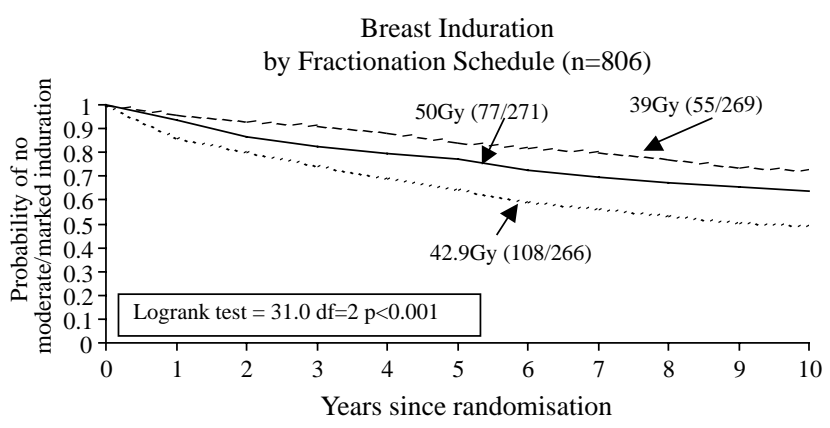

Fig. 4. Probability of palpable breast induration ten years after radiotherapy by fractionation schedule.

the dose-response relationship would be steeper in more homogenous subpopulations.

\section{Clinical assessments of breast and arm}

The effect of fractionation schedule on the physician assessments of late radiation effects is shown in Table 2. Physician assessments of overall breast cosmesis (involving an aesthetic judgement), breast shrinkage, breast distortion, breast oedema, induration and shoulder stiffness all clearly discriminated between the 39 and 42.9 Gy treatment arms, with a borderline effect on cutaneous telangiectasia. Estimates of late radiation effects for the $50 \mathrm{~Gy}$ arm were between those for 39 and $42.9 \mathrm{~Gy}$. The effect of fractionation schedule on breast induration is clearly demonstrated in Fig. 4. The estimate of the $\alpha / \beta$ value for induration is 3.1 Gy $(95 \% \mathrm{Cl} 1.8-4.4 \mathrm{~Gy})$, as shown in Table 3 . The only clinical parameter that failed to demonstrate a dose response between the 39 and 42.9 Gy treatment arms was arm oedema. This is thought to reflect the small proportion (20.6\%) of patients undergoing any form of lymphatic radiotherapy.

\section{Effect of electron boost on breast appearance and endpoints from clinical assessments}

723 patients were randomised to boost versus no boost. A further 687 patients were recommended an elective boost as part of their standard treatment. The effect of boost on photographic and clinical assessments of late radiation effects is shown in Table 4. There were statistically significantly reduced risks of induration and telangiectasia (borderline) in patients randomised to no boost (see Fig. 5 for induration). Fig. 6 shows the effect of a randomised boost on change in photographic breast appearance. The change in breast appearance is also shown for patients treated with an elective (non-randomised) boost.

\section{Discussion}

A trial design that controls for overall treatment time and incorporates 2 dose levels of a test regimen delivered in 13 , instead of 25 , fractions offers a robust test of the effects of fraction size on the late normal tissue responses of the breast. The 2 test dose levels are very useful in confirming the sensitivity of the primary endpoint (change in breast appearance) as well as important secondary 
Table 4

Survival analyses of change in breast appearance and clinical assessments of late radiation effects according to boost

\begin{tabular}{|c|c|c|c|c|c|}
\hline Endpoint & Boost & Events/total (\%) & $\begin{array}{l}\text { Estimated \% with no } \\
\text { event at } 5 \text { years } \\
(95 \% \mathrm{Cl})\end{array}$ & $\begin{array}{l}\text { Estimated } \% \text { with no } \\
\text { event at } 10 \text { years } \\
(95 \% \mathrm{Cl})\end{array}$ & $\begin{array}{l}\text { Logrank test } \\
\text { comparing all } 3 \\
\text { schedules: } P \text {-value }\end{array}$ \\
\hline \multicolumn{6}{|c|}{ Photographic assessment } \\
\hline $\begin{array}{l}\text { Any change in } \\
\text { breast appearance }\end{array}$ & $\begin{array}{l}\text { Rand. no boost } \\
\text { Rand. boost } \\
\text { Non-rand. boost }\end{array}$ & $\begin{array}{r}96 / 306(31.4) \\
117 / 309(37.9) \\
207 / 587(35.3)\end{array}$ & $\begin{array}{l}65.4(59.4-71.3) \\
59.2(53.2-65.2) \\
60.7(56.2-65.2)\end{array}$ & $\begin{array}{l}49.0(35.8-62.2) \\
46.3(35.3-57.3) \\
42.5(34.2-50.8)\end{array}$ & 0.349 \\
\hline $\begin{array}{l}\text { Marked change in } \\
\text { breast appearance }\end{array}$ & $\begin{array}{l}\text { Rand. no boost } \\
\text { Rand. Boost } \\
\text { Non-rand. boost }\end{array}$ & $\begin{array}{l}18 / 306(5.9) \\
26 / 309(8.4) \\
32 / 587(5.5)\end{array}$ & $\begin{array}{l}93.4(90.3-96.5) \\
90.5(86.9-94.1) \\
93.8(91.6-96.1)\end{array}$ & $\begin{array}{l}90.0(82.9-97.1) \\
88.1(82.2-93.9) \\
89.7(84.6-94.7)\end{array}$ & 0.302 \\
\hline $\begin{array}{l}\text { Clinical assessment } \\
\text { Cosmesis (fair/ } \\
\text { poor) }\end{array}$ & $\begin{array}{l}\text { Rand. no boost } \\
\text { Rand. boost } \\
\text { Non-rand. boost }\end{array}$ & $\begin{array}{l}127 / 230(55.2) \\
138 / 222(62.2) \\
211 / 354(59.6)\end{array}$ & $\begin{array}{l}50.6(43.8-57.3) \\
43.0(36.1-49.9) \\
43.8(38.3-49.4)\end{array}$ & $\begin{array}{l}35.8(28.1-43.5) \\
29.8(22.8-36.8) \\
30.4(24.4-36.3)\end{array}$ & 0.185 \\
\hline $\begin{array}{l}\text { Breast shrinkage } \\
\text { (moderate/marked) }\end{array}$ & $\begin{array}{l}\text { Rand. no boost } \\
\text { Rand. boost } \\
\text { Non-rand. boost }\end{array}$ & $\begin{array}{l}120 / 229(52.4) \\
123 / 222(55.4) \\
176 / 352(50.0)\end{array}$ & $\begin{array}{l}51.3(44.4-58.2) \\
49.2(42.2-56.2) \\
53.0(47.3-55.8)\end{array}$ & $\begin{array}{l}39.6(32.1-47.2) \\
34.3(26.7-41.9) \\
40.2(33.7-46.7)\end{array}$ & 0.76 \\
\hline $\begin{array}{l}\text { Breast distortion } \\
\text { (moderate/marked) }\end{array}$ & $\begin{array}{l}\text { Rand. no boost } \\
\text { Rand. boost } \\
\text { Non-rand. boost }\end{array}$ & $\begin{array}{l}107 / 230(46.5) \\
114 / 222(51.4) \\
174 / 352(49.4)\end{array}$ & $\begin{array}{l}58.7(52.0-65.4) \\
52.8(45.9-59.7) \\
49.8(44.1-55.5)\end{array}$ & $\begin{array}{l}46.3(38.5-54.0) \\
43.5(36.2-50.7) \\
41.7(35.4-48.0)\end{array}$ & 0.418 \\
\hline $\begin{array}{l}\text { Breast oedema } \\
\text { (moderate/marked) }\end{array}$ & $\begin{array}{l}\text { Rand. no boost } \\
\text { Rand. boost } \\
\text { Non-rand. boost }\end{array}$ & $\begin{array}{l}33 / 230(14.3) \\
40 / 222(18.0) \\
44 / 353(12.5)\end{array}$ & $\begin{array}{l}86.7(82.3-91.1) \\
82.7(77.6-87.8) \\
87.1(83.4-90.8)\end{array}$ & $\begin{array}{l}85.2(80.3-90.0) \\
81.2(75.8-86.6) \\
86.1(82.0-90.2)\end{array}$ & 0.243 \\
\hline $\begin{array}{l}\text { Induration (moder- } \\
\text { ate/marked) }\end{array}$ & $\begin{array}{l}\text { Rand. no boost } \\
\text { Rand. boost } \\
\text { Non-rand. boost }\end{array}$ & $\begin{array}{r}50 / 229(21.8) \\
84 / 222(37.8) \\
106 / 352(30.1)\end{array}$ & $\begin{array}{l}82.8(77.7-88.0) \\
69.4(63.0-75.9) \\
73.9(68.8-63.1)\end{array}$ & $\begin{array}{l}72.5(65.5-79.6) \\
55.5(47.8-63.1) \\
58.1(51.2-64.9)\end{array}$ & 0.001 \\
\hline $\begin{array}{l}\text { Telangiectasia } \\
\text { (moderate/marked) }\end{array}$ & $\begin{array}{l}\text { Rand. no boost } \\
\text { Rand. boost } \\
\text { Non-rand. boost }\end{array}$ & $\begin{array}{l}19 / 228(8.3) \\
38 / 222(17.1) \\
41 / 354(11.6)\end{array}$ & $\begin{array}{l}93.2(89.8-96.7) \\
86.9(82.1-91.7) \\
89.4(85.8-93.0)\end{array}$ & $\begin{array}{l}91.2(87.1-95.2) \\
77.2(70.7-83.8) \\
83.5(78.6-88.4)\end{array}$ & 0.026 \\
\hline $\begin{array}{l}\text { Arm swelling (mod- } \\
\text { erate/marked) }\end{array}$ & $\begin{array}{l}\text { Rand. no boost } \\
\text { Rand. boost } \\
\text { Non-rand. boost }\end{array}$ & $\begin{array}{l}12 / 230(5.2) \\
16 / 222(7.2) \\
27 / 354(7.6)\end{array}$ & $\begin{array}{l}96.1(93.4-98.8) \\
93.3(89.8-96.8) \\
92.2(89.1-95.3)\end{array}$ & $\begin{array}{l}93.2(89.0-97.4) \\
91.7(87.5-95.8) \\
90.5(86.8-94.1)\end{array}$ & 0.413 \\
\hline $\begin{array}{l}\text { Shoulder stiffness } \\
\text { (moderate/marked) }\end{array}$ & $\begin{array}{l}\text { Rand. no boost } \\
\text { Rand. boost } \\
\text { Non-rand. boost }\end{array}$ & $\begin{array}{l}27 / 229(11.8) \\
26 / 222(11.7) \\
35 / 353(9.9)\end{array}$ & $\begin{array}{l}90.6(86.7-94.6) \\
91.9(88.2-95.6) \\
90.1(86.8-93.5)\end{array}$ & $\begin{array}{l}85.4(80.8-89.9) \\
84.6(78.8-90.4) \\
87.8(83.8-91.8)\end{array}$ & 0.873 \\
\hline
\end{tabular}

endpoints. Assuming linearity between the 2 test dose levels, the 13-fraction schedule that is iso-effective with $50 \mathrm{~Gy}$ in 25 fractions can be determined by interpolation. Based on these estimates, the sensitivity to fraction size (expressed as the $\alpha / \beta$ value) can be determined directly for several radiation-related endpoints, including change in breast appearance and palpable induration. The $\alpha / \beta$ value of $3.6 \mathrm{~Gy}(95 \% \mathrm{Cl} 1.8-5.4)$ for change in breast appearance is consistent with indirect estimates of fractionation sensitivity in a range of human non-neural late-responding tissues $[16,17]$. The direct estimate of fractionation sensitivity for marked changes in breast appearance is very similar to this value. It is noticeable (see Fig. 2 for example) that a clear dose response for all endpoints was established by 12 months, but estimates of iso-effect were not altered by confining analyses to first events scored after 12 or 24 months.

A highly significant relationship was found between the dose delivered in 13 fractions and the resulting change in the incidence of changed breast appearance $(P=0.0002)$. The steepness of this relationship was quantified by the $\gamma$-value and this was estimated at 1.8 . Thus, a, $5 \%$ increment in total dose is estimated to cause a 9percentage-point increase in the proportion of patients with marked changes in breast appearance. This illustrates the importance of precise estimation of biologically equivalent doses when modifying dose-fractionation schedules for postoperative radiotherapy for breast cancer, in good concordance with the published literature in this field.

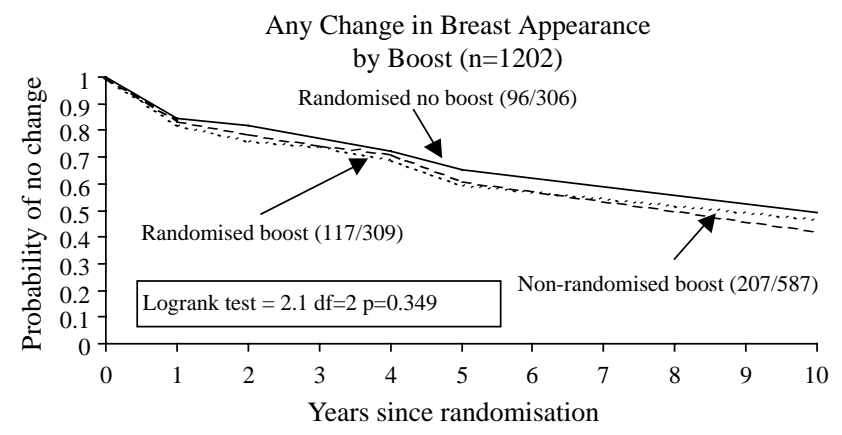

Fig. 5. Probability of any change in breast appearance late radiation effect ten years after radiotherapy according to breast boost. 


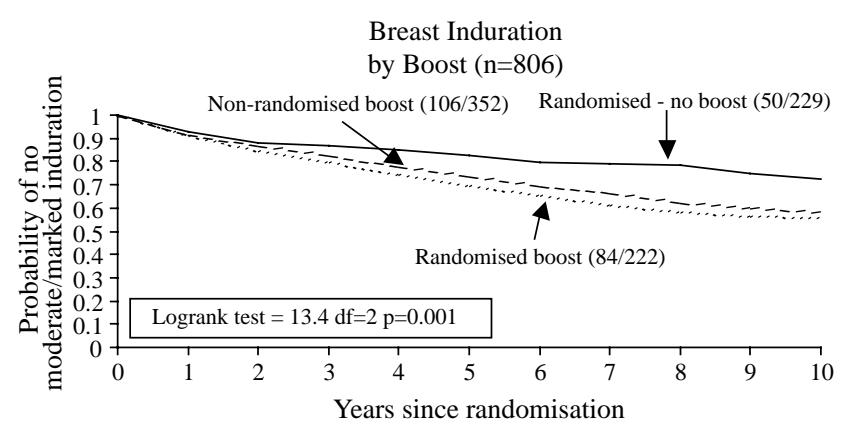

Fig. 6. Probability of palpable breast induration ten years after radiotherapy according to breast boost.

Clinical assessments of breast induration also discriminate between the 2 test dose levels despite being performed by a large number of clinicians over a period of many years. The $\alpha / \beta$ value of $3.1 \mathrm{~Gy}(95 \% \mathrm{Cl} 1.8-4.4)$ for palpable induration does not differ significantly from the photographic endpoint. Taking a conservative estimate of $3.0 \mathrm{~Gy}$ for the $\alpha / \beta$ value of dose-limiting normal tissue responses in the breast, the delivery of 39.0 in $3.0 \mathrm{~Gy}$ fractions over 5 weeks is iso-effective with 46.7 in $2.0 \mathrm{~Gy}$ equivalents (fractions). The delivery of 42.9 in $3.3 \mathrm{~Gy}$ fractions over 5 weeks is iso-effective with 53.9 in $2 \mathrm{~Gy}$ equivalents. By interpolation, $50 \mathrm{~Gy}$ in 25 fractions is iso-effective with 40.8 in 13 fractions of $3.14 \mathrm{~Gy}$ over 5 weeks. If the $\alpha / \beta$ value for dose-limiting late normal tissue responses in the breast is $4.0 \mathrm{~Gy}$, the 2 test regimens are equivalent to 45.5 and $52.2 \mathrm{~Gy}$, respectively, in $2.0 \mathrm{~Gy}$ equivalents, and $50 \mathrm{~Gy}$ in 25 fractions is iso-effective with $41.6 \mathrm{~Gy}$ in 13 fractions of 3.2 Gy over 5 weeks.

In scoring change in photographic breast appearance, no attempt was made to score cosmesis, a term which implies an aesthetic judgement. The photographic endpoint restricted itself to changes in size and shape of the breast compared to the post-surgical baseline, using the contralateral breast as a control for time-related changes in appearance. Size change was dominated by shrinkage, although a minority of women scored an event by virtue of breast swelling at the 12 months assessment. In a proportion of these women, swelling was related to simple breast oedema, associated with visible linear indentations on the skin caused by the patient's brassiere. In others, the overlying skin looked stretched, shiny and erythematous. Although bacterial cellulitis or cutaneous tumour recurrence could not be excluded on the basis of a photograph alone, the appearances in this minority of patients were entirely consistent with a post-radiation syndrome that presents a few months after radiotherapy with inflammatory symptoms and signs (breast pain and swelling, tenderness and erythema confined within the treatment volume), and resolves over several months [20].

Change in breast shape (distortion with nipple retraction) was particularly noticeable after large resections from the axillary tail or inframammary regions of the breast. Since telangiectasia was infrequent on a photograph, being concealed in skin folds, this feature was ignored. From the above account, it is clear that although change in breast appearance is a clinically valid and reproducible endpoint, it is influenced by response in more than one tissue type (skin, subcutaneous fat, glandular epithelium, pectoral muscle). This is not a limitation, but it serves as a reminder that there are different radiation phenotypes to consider that lie beyond the reach of photography, including effects on bone and underlying lung and heart. The outcome data generated by the clinical assessments of palpable induration are, therefore, reassuring in generating comparable fractionation sensitivities.

Although these data provide the most precise estimates to date of the fractionation sensitivity of late normal tissue responses in human breast, they are of limited clinical value without estimating the fractionation sensitivity of breast cancer. The current trial dataset has been incorporated into the UK Standardisation of Radiotherapy (START) trial to increase statistical power of estimating anti-tumour effect [19]. For this reason, full publication of the current tumour control data has not yet been authorised by the START Trial Steering Committee. However, the tumour control data have been presented in a published abstract, which generate an $\alpha / \beta$ value for ipsilateral local tumour control of $4.1 \mathrm{~Gy}(95 \% \mathrm{Cl}$ 1.0-9.7) [12]. The wide confidence intervals reflect the relatively small number of tumour-related events, but the point estimate is entirely consistent with the hypothesis under test in the trial. Recent results of a Canadian randomised trial of 1100 patients report virtually identical ipsilateral tumour recurrence rates after $50 \mathrm{~Gy}$ in 25 fractions and $42.5 \mathrm{~Gy}$ in 16 fractions over 22 days to the whole breast following tumour excision [18]. Assuming these two schedules are truly iso-effective, and ignoring the difference in treatment time (22 days versus 35 days), the $\alpha / \beta$ value for tumour response is $<3.0 \mathrm{~Gy}$. If, however, breast cancer response is time dependent, the implication would be that the $\alpha / \beta$ value for tumour response is higher than 3.0 Gy.

The clinical implications for fractionation regimens will be profound if it is reliably demonstrated that the average fractionation sensitivity of breast cancer is similar to the dose-limiting normal tissues of the breast. There would then be no reason to prefer $2.0 \mathrm{~Gy}$ fractions, and the challenge would be to determine the limits of hypo-fractionation. In the meantime, it would lend strong support to the adoption of commonly used schedules based on daily fractions of $2.67 \mathrm{~Gy}$ (to total doses of 40.0 or $42.5 \mathrm{~Gy}$ ). If the $\alpha / \beta$ value for tumour control is $4.0 \mathrm{~Gy}, 42.5 \mathrm{~Gy}$ in 16 fractions would be equivalent to 47.1 in $2.0 \mathrm{~Gy}$ fractions in terms of tumour control (ignoring differences in treatment time), and equivalent to 50 in $2.0 \mathrm{~Gy}$ fractions in terms of late normal tissue effects assuming an $\alpha / \beta$ value of $3.0 \mathrm{~Gy}$. The $2.9 \mathrm{~Gy}$ loss of anti-tumour effect is not likely to be clinically relevant. Based on modelling of clinical data for breast cancer control, one excess breast recurrence would occur for every 200 women treated [2]. A potential loss of therapeutic ratio might be offset by shortened treatment times, less scope for tumour repopulation and more efficient scheduling with primary surgery and adjuvant/neo-adjuvant systemic therapies.

The results of this trial confirm that clinical assessments and scoring changes in breast photographic appearance offer sensitive measures of late radiation effects, although a close relationship between these endpoints and patient selfassessments of breast cosmesis, body image, functional 
outcome and impact on quality of life cannot be assumed $[13,14]$. In theory, it is possible to estimate an $\alpha / \beta$ value for a patient-derived functional endpoint, but this is not addressed by the current study. It is also possible that the fractionation sensitivity of specific critical tissues including pectoral muscle and rib cage differ from those responsible for change in breast appearance. These obvious and important points are addressed by the current UK START trial that tests the safety and effectiveness of schedules delivering fractions of greater than 2.0 Gy in women requiring post-operative radiotherapy for early breast cancer. In this trial, tumour control is the primary endpoint, but detailed patient self-assessments of functional outcome and quality of life will help to address these uncertainties. It is likely that uncertainties relating to the effects of hypofractionation on the heart are best addresses by shielding or excluding this organ from the treatment volume. Adverse effects on lung are best addressed by minimising the volume of tissue exposed. There were no recorded cases of brachial plexopathy in the 290 women who had radiotherapy to the axilla and/or supraclavular fossa, but hypofractionation to these sites must be considered very carefully in view of the high sensitivity of the brachial plexus to fraction size.

In conclusion, the fractionation sensitivities of the normal tissues of the breast are consistent with expectations based on the existing literature. If the fractionation sensitivity of breast cancer is comparable, this opens the way for further research into the applications of hypofractionation to breast radiotherapy. Technology is now capable of exploiting hypofractionation in interesting ways, since modulation of fraction size across the breast is potentially superior to modulation of fraction numberas a way of matching of matching dose intensity to tumour recurrence risk.

\section{Acknowledgements}

are due to all the patients who participated in this study. Acknowledgements are also due to a large number of colleagues who contributed to the design, implementation and analysis of this study over many years, including Dr Ingela Turesson, University Hospital, Uppsala, Sweden; Dr Mike Henk and Dr Diana Tait, Royal Marsden Hospital, Sutton, UK; Mr Stephen Ebbs, Mayday University Hospital, Croydon, UK; Dr Kim Benstead and Dr Sean Elyan, Gloucestershire Oncology Centre, Cheltenham, UK. The trial was supported in part by Marks and Spencer plc. The ICR-CTSU receives funding from Cancer Research UK.

* Corresponding author. J. Yarnold, Academic Radiotherapy Department, The Royal Marsden Hospital, Downs Road, Sutton, Surrey SM2 5PT, UK. E-mail address: john.yarnold@icr.ac.uk

Received 28 July 2004; received in revised form 17 January 2005; accepted 26 January 2005; available online 16 March 2005

\section{References}

[1] Bates T. Hypofractionation and the therapeutic ratio. Int J Radiat Oncol Biol Phys 1989;17:443.

[2] Bentzen SM. High-tech in radiation oncology: should there be a ceiling? Int J Radiat Oncol Biol Phys 2004;58:320-30.
[3] Bentzen SM, Baumann M. The linear-quadratic model in clinical practice. In: Steel GG, editor. Basic clinical radiobiology. London: Arnold; 2002. p. 134-46.

[4] Bentzen SM, Ruifrok AC, Thames HD. Repair capacity and kinetics for human mucosa and epithelial tumors in the head and neck: clinical data on the effect of changing the time interval between multiple fractions per day in radiotherapy. Radiother Oncol 1996;38:89-101.

[5] Brenner DJ. Hypofractionation for prostate cancer radiotherapy-what are the issues? Int J Radiat Oncol Biol Phys 2003;57:912-4.

[6] Cohen L. Radiotherapy in breast cancer I. The dose-time relationship theoretical considerations. Br J Radiol 1952;25: 636-42.

[7] Douglas BG. Superfractionation: its rationale and anticipated benefits. Int J Radiat Oncol Biol Phys 1982;8:1143-53.

[8] Douglas BG, Castro JR. Novel fractionation schemes and high linear energy transfer. Prog Exp Tumor Res 1984;28:152-65.

[9] Fletcher GH. Hypofractionation: lessons from complications. Radiother Oncol 1991;20:10-15.

[10] Fowler JF. The linear-quadratic formula and progress in fractionated radiotherapy. Br J Radiol 1989;62:679-94.

[11] McKinna F, Gothard L, Ashley S, et al. Selective avoidance of lymphatic radiotherapy in the conservative management of women with early breast cancer. Radiother Oncol 1999;52: 219-23.

[12] Owen JR, Yarnold JR, Ashton A, et al. Fractionation sensitivity of the breast: results of a randomised trial. Eur J Oncol Suppl 2003;1:S9.

[13] Sneeuw KC, Aaronson NK, Yarnold JR, et al. Cosmetic and functional outcomes of breast conserving treatment for early stage breast cancer. 1. Comparison of patients' ratings, observers' ratings, and objective assessments. Radiother Oncol 1992;25:153-9.

[14] Sneeuw KC, Aaronson NK, Yarnold JR, et al. Cosmetic and functional outcomes of breast conserving treatment for early stage breast cancer. 2. Relationship with psychosocial functioning. Radiother Oncol 1992;25:160-6.

[15] Suit H, Skates S, Taghian A, et al. Clinical implications of heterogeneity of tumor response to radiation therapy. Radiother Oncol 1992;25:251-60.

[16] Thames HD, Bentzen SM, Turesson I, et al. Time-dose factors in radiotherapy: a review of the human data. Radiother Oncol 1990;19:219-35.

[17] Thames HD, Hendry JH, Moore JV, et al. The high steepness of dose-response curves for late-responding normal tissues. Radiother Oncol 1989;15:49-53.

[18] Whelan T, MacKenzie R, Julian J, et al. Randomized trial of breast irradiation schedules after lumpectomy for women with lymph node-negative breast cancer. J Natl Cancer Inst 2002;94: 1143-50.

[19] Winfield E, Deighton A, Venables K, et al. Survey of UK breast radiotherapy techniques: background prior to the introduction of the quality assurance programme for the START (standardisation of radiotherapy) trial in breast cancer. Clin Oncol (R Coll Radiol) 2002;14:267-71.

[20] Winkelmann RK, Grado GL, Quimby SR, Connolly SM. Pseudosclerodermatous panniculitis after irradiation: an unusual complication of megavoltage treatment of breast carcinoma. Mayo Clin Proc 1993;68:122-7.

[21] Yarnold J.R., Owen J.R., Ashton A., et al. Fractionation sensitivity of change in breast appearance after radiotherapy for early breast cancer: long-term results of a randomised trial. Radiother Oncol 2002;64 Supplement 1:S25. 